УДК.621.922

DOI: https://doi.org/10.26642/ten-2020-1(85)-30-36

Танович Любодраг, д.т.н., проф. Университет в Белграде

\title{
Исследования в области развития нового поколения металлообрабатывающих станков и процессов
}

\begin{abstract}
Опубликованная работа содержит обзор исследований в области развития нового поколения металлообрабатывающих станков для изготовления компонентов размером всего несколько миллиметров, но с высокой точностью и из различных материалов. Показано новые, недавно разработанные микромашины, имеющие возможности изготовления широкой гаммы продукиии. Во второй части работь показано часть исследований в этой области, осуществляющихся на машиностроительном факультете Белградского университета на кафедре производственных прочессов в машиностроении.
\end{abstract}

Ключевые слова: миниатюризация; микрорезание; металлообрабатывающие станки; проиессы; инструментыл.

Введение. Микропроизводство подразумевает создание продукта высокой точности размеров и форм из различных материалов величиной в пределе от нескольких микрометров до нескольких миллиметров [1]. Начало микропроизводства было положено в конце восьмидесятых годов развитием Микроэлектромеханических систем (MEMS). Высокий рост спроса на миниатюризованные компоненты, которых характеризуют внешний вид точных размеров, функция, уменьшенный расход энергии, дизайн, высокая точность и превосходные возможности в области обороны, медицины, биотехнологии, телекоммуникации и энергетики, также побудил большой интерес в области микропроизводства как в научно-исследовательских учреждениях, так и в промышленности во всем мире. [2]. Сегодня микропроизводство интенсивно развивается как ответ на повышающийся спрос на миниатюризованную продукцию, которая часто изготовляется в маленьких количествах, может быть сложных видов и особенного качества поверхности. На рисунке 1 показаны примеры микропродуктов, а на рисунке 2 промышленные микропроизводственные системы.

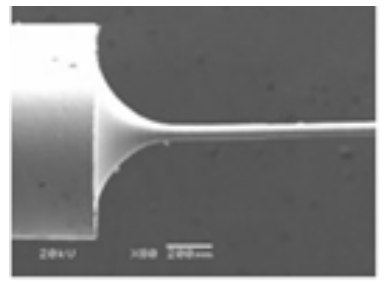

a)

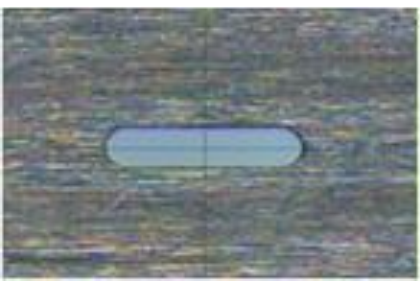

б)

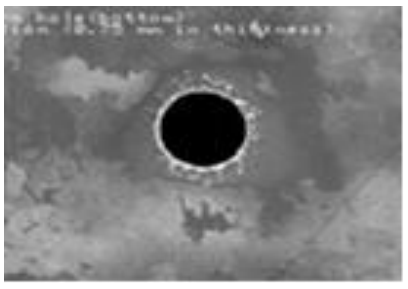

в)

Рис. 1. Вал диаметром 30 мкм (а), паз шириной 100 мкм (б), отверстие диаметром 50 мкм

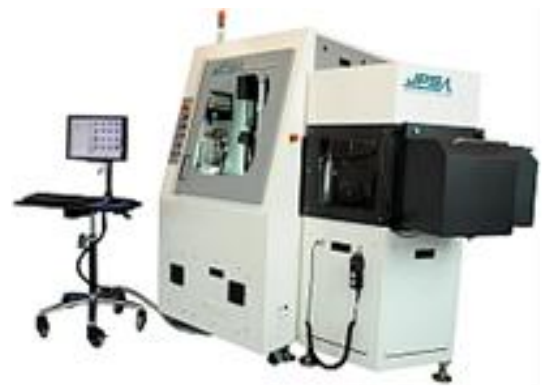

a)

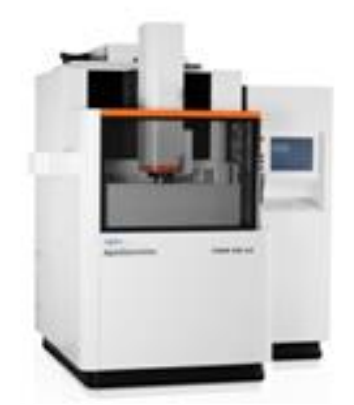

б)

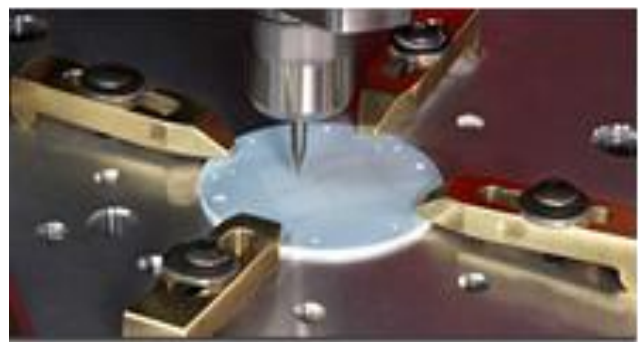

8)

Puс. 2. Промышленные микромашины: а) лазерная система; б) микро-ЕDМ машина [3]; в) стенд для микросверления 
У миниатюризации есть все преимущества стать ведущей технологией XXI века, что обосновано такими фактами:

а) промышленно развитые страны делают свой вклад в эту область привлекая исследовательские институты на уровне миллиардов долларов США с тенденцией экспоненциального вклада в будущем;

b) производство миниатюрных инженерных систем и устройств с микро- и наноразмерами станет доминирующим экономическим фактором развития в будущем;

c) в трансформации существующих процессов на будущее ориентированные физическохимическо-биологические процессы не будет непосредственной парадигмы. Промышленность и образовательные учреждения должны быть подготовлены к таким переменам;

d) странам, у которых не будет трансформации своей перерабатывающей промышленности и образовательной системы от традиционных к ориентированным миниатюризованным процессам и продукции, не удастся использовать свою экономическую прибыль от этой революции в истории.

Многие виды промышленности требуют изготовления миниатюрных компонентов, для которых характерно уменьшение энергии и материала, используемых в производстве, связь с электроникой, упрощение системы, расходы/перформансы преимущества, скорость, увеличение чувствительности и селективности, эксплуатация новых эффектов и т. д.

Микрообработка и системы. Микропроизводственные процессы могут быть разделены на четыре главные категории: субстрактивные, адитивные, форминг и гибридные:

a) субстрактивные процессы подразумевают: микромеханическую обработку (точение, сверление, фрезование, шлифование), микроэлектроэрозионную обработку (EDM), микрохимическую обработку (ЕСM), микролазерную обработку (FIB);

b) адитивные процессы подразумевают: селективное лазерное спекание (SLS), стереолитографию (SLA) и 3D принтеры;

c) форминг-процессы подразумевают: микропрокатку, микролитье, микролитье под давлением, микровыдавливание и т. п.;

d) гибридные процессы подразумевают: два или больше микроконвенциальных процесса в целях обработки твердых материалов или улучшения обрабатывающих характеристик и точности обработки.

Механические микрообрабатывающие процессы в основном - модифицированые или простые конвенциальные макромеханические обрабатывающие процессы, не учитывая разницы, обусловленные размерами и закономерностями, действующими в этой области. Хорошая геометрическая взаимосвязь между инструментом и обрабатывающей поверхностью характеризует эти процессы. Это подразумевает использование инструмента с острой режущей кромкой и маленьким радиусом закругленности. Одним из доминирующих факторов при микрорезании является отношение глубины резания и радиуса закругленности режущей кромки, приводящий к так называемому эффекту минимальной толщины стружки. При этом определяется предельная глубина резки, ниже которой не образуется стружка. Механика процесса резко отличается от макроразмеров, поскольку тут доминирующим является механизм царапания относительно классического скалывания. Дополнительные характеристики этого процесса включают в рассмотрение зернистую структуру материала и все возможные источники ошибок в нем, приводящие к нестабильности процесса.

Возникает вопрос, связанный с пояснением микрообаботки.

Первая точка зрения:

- микрообработка является совокупностью всех операций, реализующихся на компонентах микро/мезоразмеров и изделий в пределе с 100 кмк до 10 мм;

- $\quad$ микрообработку характеризуют требования к производству высокоточных изделий комплексных геометрических форм широкой гаммы материалов в определенном пределе размеров;

- $\quad$ микрообработка подразумевает использование специальных инструментов (микроинструмент диаметром 50-500 кмк), маленькую толщину стружки (субмикронная до нескольких микронов) и скорость $\left(50 \mathrm{~K}-200 \mathrm{~K} \mathrm{мин}^{-1}\right)$.

Последствием главной разницей между макро- и микрорезанием является преобладание скольжения и царапания над скалыванием и необходимость обязательного учета микроструктурных эффектов.

Вторая точка зрения: определение микрообработки с точки зрения размеров толщины стружки можно классифицировать на:

- $\quad$ микроразмеры стружки: обработка в конвенциальных режимах, при чем толщина стружки в десять раз больше закругленности режущей кромки и в процессе преобладает скалывание. При этом микроструктурные эффекты не заслуживают внимания. Значение толщины стружки больше 10 кмк;

- $\quad$ микро/мезоразмеры стружки: эту обработку характеризирует преобладание царапания, трения, упругих и пластических деформаций с учетом, что радиус закругленности режущей кромки приблизительно равный толщине стружки. Толщина стружки - в пределах от сибмикро до несколько микрометров; 
- $\quad$ наноразмеры стружки: это определение обычно связано с ультраточной обработкой алмазными инструментами, имеющими возможность заточки без радиуса или с маленьким радиусом закругленности таким образом, что толщина стружки может быть в пределах нанометра.

На вопрос: что обусловило направление развития микромашин, ответ можно найти в необходимости развития новых микроизделий, которые можно изготовить на таких машинах, ограничено доступных к использованию, то есть с большой экономией энергии и сбережением окружающей среды. При этом необходимо указать на проблемы, присутствующие у таких машин: управляемость осей, большая передвижная масса, ограниченное ускорение, необходимы ультрабольшие числа оборотов шпинделя, неточность микроинструментов и маленькая точность изготовления. Указанные проблемы могут частично решиться несколькими способами: уменьшением передвижных масс, исчезновением необходимости шпинделя, развитием алгоритмов и контрольной стратегии за достижением требуемой топографии поверхности, введением активной компенсации.

Исследования в области микрорезания гранита. Обработка шлифованием возникает за счет суммирования действий любой абразивной частицы, проявляясь посредством деформации и разрушения, но механизм микродеформаций и микрорезаний в зоне обработки отличается в зависимости от параметров обработки и неоднородности обрабатывающего материала. Исследования в области взаимодействия между инструментом и материалом, происходящим из горной породы, проводились в трех направлениях. Отождествление процесса вдавливания индентора с работой алмазного зерна в шлифовальном круге, затем выполнение процесса микрорезания выделенным алмазным зерном и в конце - выполнением процесса шлифования.

В состав первой группы исследований вошли анализ влияния формы зерна (угол верха, радиус закругления) и способ вдавливания (статическое, динамическое) на развитие трещин.

Вторая группа исследователей выполняла процесс микрорезания выделеннием алмазных зерен на различных хрупких материалах, литературные источники гипотез об этапах образования стружки резко отличаются друг от друга, они даже противоречат друг другу.

Третья группа исследователей выполняла реальные процессы резания и шлифования хрупких материалов. При этом они проводили анализ механизма формирования трещин и хрупкое разрушение материала. Они измеряли силы, силу резания и изнашивание инструмента при обработке керамики и гранита, чтобы дать рекомендацию для эффективной абразивной обработки.

Схема микрорезания.

Процесс микрорезания был выполнен следующим способом. Алмазное зерно конической формы с углом $120^{\circ}$ поставлено сверху и сильно прикреплено на алюминииевый диск диаметром 150 мм, после статически и динамически сбалансированно. На рабочем стенде машины НМС 500 установлено динамометр, на нем зажимной прибор и в нем образцы их гранита. Зажимной прибор обеспечивает поворот образца под наклон (1:200). Посредством аксиального смещения платформы с динамометром скоростью Vw выполнялось микрорезание с изменяемой глубиной резания (рис. 3). Наклон 1:200 обеспечивает осуществление изменяемой глубины проникновения зерна до 0,28 мм.
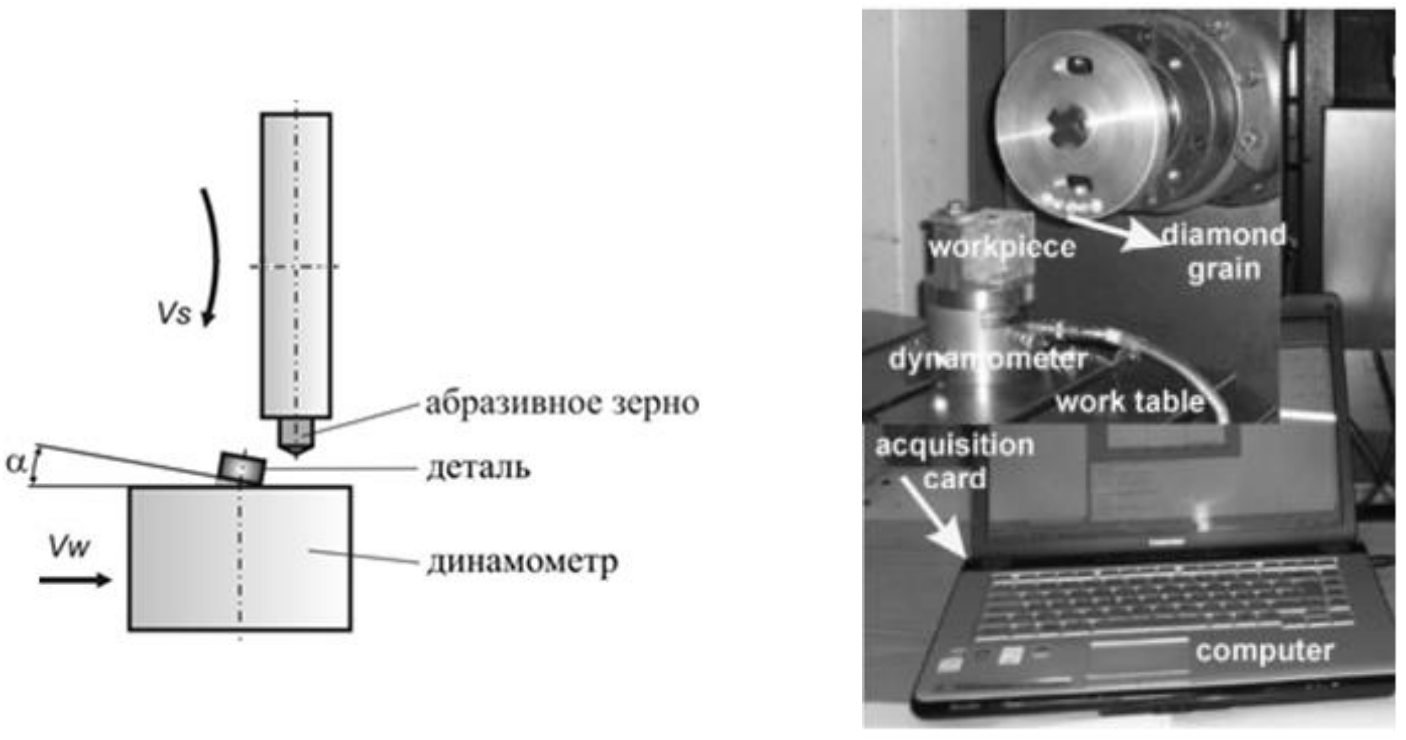

Рис. 3. Установка для измерения сил микрорезания: вращзательное движение алмазного зерна $(V s)$ и аксиальное движение детали $(V w)$ 
Экспериментальные результаты.

Процесс микрорезания был выполнен с двумя видами гранита - «Йосаница» (ГЙ) мелкозернистой структуры и «Буковик» (ГБ) среднезернистой структуры, физическо-механические свойства которых были испытаны и показаны в таблице 1.

Таблица 1

Физическо-механические свойства гранита

\begin{tabular}{|l|c|c|}
\hline \multirow{2}{*}{\multicolumn{1}{|c|}{ Свойства }} & \multicolumn{2}{|c|}{ Гранит } \\
\cline { 2 - 3 } & «Йосаница» (ГЙ) & «Буковик» (ГБ) \\
\hline Удельный вес, $\mathrm{KN} / \mathrm{m}^{3}$ & $29,70 \pm 0,3$ & $25,6 \pm 0,1$ \\
\hline Микротвердость, НК75/HK25 & 3,1 & 2,6 \\
\hline Прочность на сжатие, МРа & $185 \pm 20$ & $102 \pm 8$ \\
\hline Прочность на растяжение, МРa & $16,6 \pm 1$ & $15,0 \pm 2$ \\
\hline Кохезия, МРа & 31,8 & 22,0 \\
\hline Коэффициент абразивности, \% & $21,5-23,0$ & $23,5-24,5$ \\
\hline
\end{tabular}

Значения указаных выше свойств определены по типу средних значений большого количества измерений в зависимости от петрографической природы гранита. На основании измерений замечено, что ГБ есть более однообразным и имеет твердость меньше чем у ГЙ.

При проведении экспериментов было использовано следующее измерительное оборудование: двухкомпонентный динамометр Kistller 5007, «аквизиционная карточка» $+10 \mathrm{~V} 105 \mathrm{kHz}$, компьютер, микроскоп Leitz wetzlar c Sony видеокамерой (рис. 3)

На рисунке 4 показаны диаграммы изменения нормальной составляющей силы резания в функции глубины проникновения зерна при скоростях $\mathrm{Vs}=7,85-15,7$ м/с. Эти результаты являются средним значением сорока измерений с отклонением с $\pm 10 \%$ у ГЙ и $\pm 5 \%$ у ГБ. На основании полученных зависимостей можем сделать вывод, что с увеличением скорости проникновения зерна растет сопротивление резания у обеих видов гранита. То, что сопротивление выше при обработке гранита ГЙ относительно ГБ, связоно с его более выраженной твердостью и прочностью.

Нелинейность изменения Рн является последствием неоднородности (негармоничности) гранита. Также с увеличением глубины проникновения зерна увеличивается сила резания (кроме мест где фиксируется падение, что есть последствием мягкой фазы в граните).

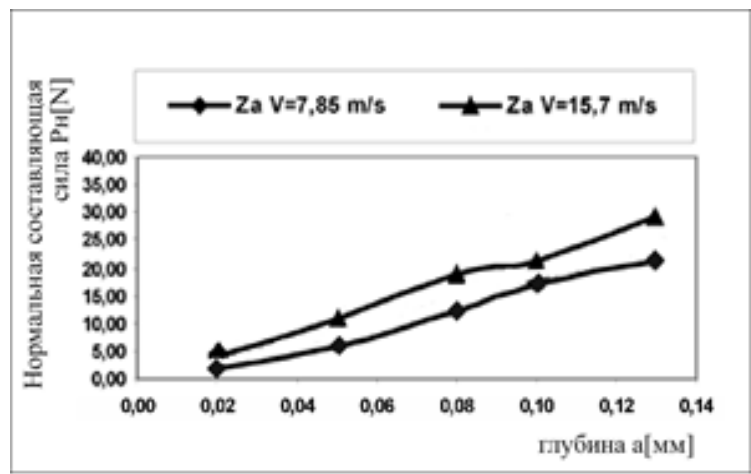

a)

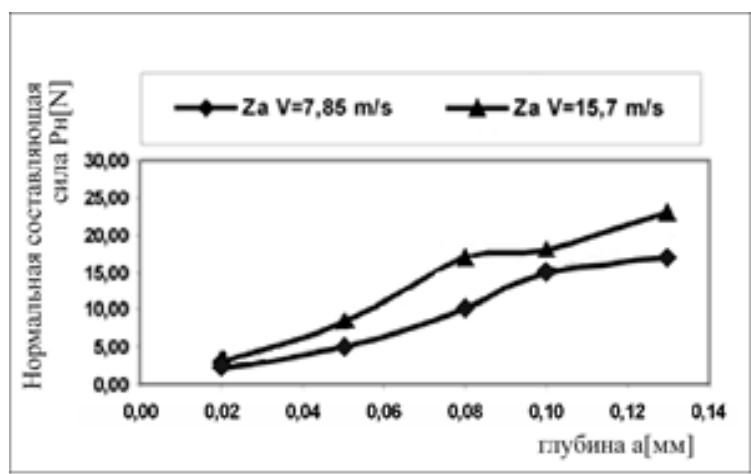

б)

Рис. 4. Измерение составляющей силь резания в функции глубины проникновения зерна при микрорезке гранита: а) ГЙ; б) ГБ

У гранита ГБ твердость меньше чем у гранита ГЙ и во время микрорезании, при одинаковых глубинах проникновения радиальные трещины меньше выражены у гранита ГБ. Анализ следов на граните сведетельствует о более выраженном выкрашивании у гранита ГБ, что является последствием более крупной структуры и большего вырывания зерна.

Измерением уставновлена критическая глубина проникновения зерна у гранита ГЙ, составляющая 0,020 мм $(\mathrm{Vs}=7,85 \mathrm{~m} / \mathrm{s})$ и она уменьшается на 0,015 мм с увеличением скорости на $15,7 \mathrm{~m} / \mathrm{s}$. При одинаковых условиях проникновения и выполнения процесса у гранита ГБ предельная глубина проникновения есть чуть больше и она составляет от $0,022 \mathrm{mм}(\mathrm{Vs}=7,85 \mathrm{~m} / \mathrm{c})$ до 0,018 мм $(\mathrm{Vs}=15,7 \mathrm{~m} / \mathrm{c})$.

На рисунках 5-6 показаны схема микрорезания (аксиальное движение алмазного зерна -Vпр) и диаграммы изменения нормальной составляющей силы сопритивления резанию в функции глубины 
проникновения зерна при скоростях Vпр = 1-2-4-5 м/мин. при обработке гранита. На основании полученных зависимостей можно сделать вывод, что с повышением скорости проникновения глубины увеличивается сопротивление разанию у обеих видов гранита. Однако оно бывает больше при обработке гранита ГЙ, чем гранита ГБ, что является последствием большей твердости и прочности. Рост скорости резания с 1 до 4 м/мин. приводит у гранита ГЙ к росту силы Рн на около 50 \%, а у гранита ГБ за около $30 \%$, что можно объяснить большим растрачиванием значения твердости.

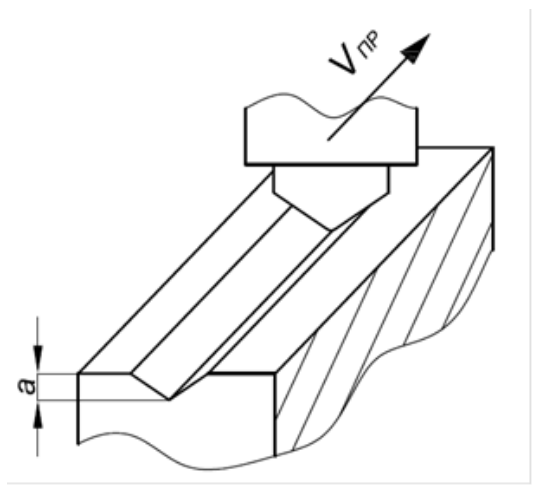

Рис. 5. Схема микрорезания: аксиальное движение алмазного зерна (Vnp)
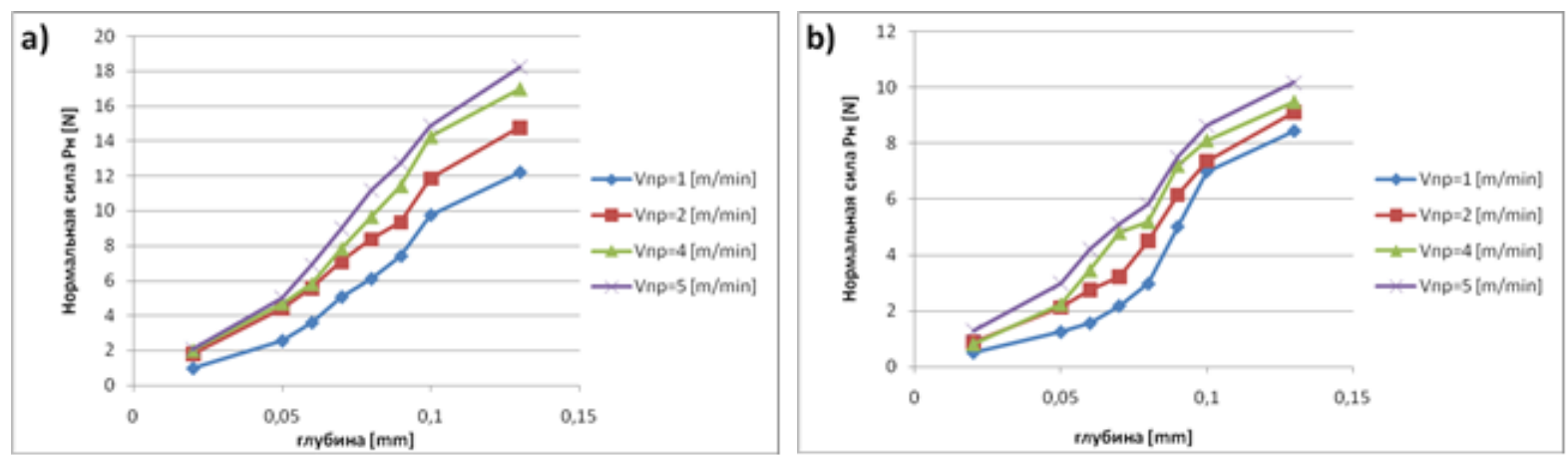

Рис. 6. Изменение сопротивления резанию при микрорезании гранита: а) ГЙ; b) ГБ

Анализом следов микрорезания указанных выше гранитов возможно описать механизм формирования стружки (рис. 7).

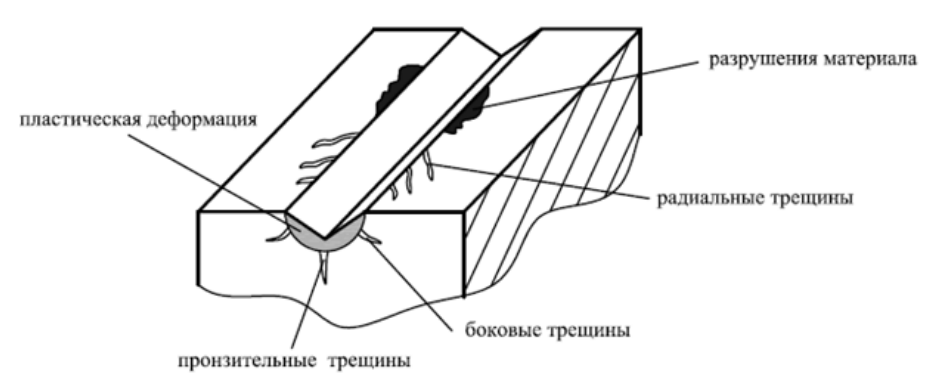

Рис. 7. Иллюстращия образования стружки у гранитов

При меньших глубинах проникновения алмазного зерна перед зерном в зоне ядра разрушения возникает пластическая деформация с возникновением проникновенных и боковых трещин.

C увеличением глубины резания указанные трещины увеличиваются таким образом, что боковые трещины достигают поверхности обрабатываемой части и получают форму радиальных трещин. В определенный момент происходит их взаимосвязь и возникает выкрошивание, дробление и вываливание зерен гранита, вызывая неравномерное выкрошивание вдоль канала, сформированного из алмазного зерна. 
При микрорезании гранита хорошо видно два места, которые можно разграничить глубиной проникновения зерна (критическая глубина проникновения) и которые разделяет место пластической деформации, сопровождающейся возникновением трещин от места наличия отделения блоков обрабатываемого материала. Критическая глубина проникновения может быть одним из критериев оптимизации процесса шлифования.

Механизм обработки гранита отличается хруким разрушением и пластической деформацией. Хрупкое разрушение указывает на два механизма создания трещин: глубокие, влияющие на уменьшение прочности и боковые/радиальные, участвующие в формировании стружки.

У гранита ГБ твердость меньше чем у гранита ГЙ и при микрорезании при одинаковых глубинах проникновения радиальные трещины меньше выражены у гранита ГБ. Анализ следов на граните сведетельствует о более выраженом выкрошивание у гранита ГБ, что является последствием более крупной структуры и большего вырывания зерна.

Вывод. Проведенные исследования обеспечили установление критической глубины проникновения зерна, а тем самым и обработки гранита и изменения нормального компонента сопротивления резания в функции скорости и глубины проникновения зерна.

Под обрабатываемой поверхностью остаются трещины, возникшие не только в процессе создания гранита, а и в течении процесса обработки, что может значительно повлиять на прочность этой части. В связи с этим необходимо стремиться к тому, чтобы трещины, возникшие в процессе обработки, были минимальных размеров, иначе отделение блоков обрабатываемого материала будут меньшего объема, а соответствующие характеристики качества обработанной поверхности - ниже.

Сравнивая следы микрорезания на граните ГЙ и ГБ, замечено, что мелкозернистые варианты структур гранита более подходят к обработке, потому что возникновение выкрошивания и вырывания зерна выражено меньше относительно к крупнозернистым структурам.

Критическая глубина проникновения зерна больше у ГБ, чем у гранита ГЙ, что объясняется более выраженным присутствием мягкой фазы и меньше выраженной твердостью.

Сравнивая силы при микрорезании можно сделать вывод, что при одинаковых глубинах и скоростях резания сила резания до 40 \% больше у ГЙ, чем у ГБ, что объясняется более выраженной твердостью.

В экспериментах использованы алмазные зерна одинаковой формы и размеров отдельно для каждого гранита и на них не замечено выраженное изнашивание.

\section{Список использованной литературы:}

1. Micromanufacturing: International Assessment of Research and Development / K.F. Ehmann, D.Bourell, M.L. Culpepper and other // Springer. - 2007.

2. Katz Z. Analysis of Micro-scale EDM Process / Z.Katz, C.J. Tibbles // The International Journal of Advanced Manufacturing Technology. - 2005. - Vol. 25. - P. 923-928.

3. [Electronic resource]. - Access mode : www.jpsalaser.com.

4. Saotome Y. An in-situ incremental microforming system for three-dimensional shell structures of foil materials / Y.Saotome, T.Okamoto // Journal of materials processing technology. - 2001. - Vol. 113. - 636 p.

5. Glavonjic M. Functional simulator of 3-axis parallel kinematic milling machine / M.Glavonjic, D.Milutinovic, S.Zivanovic // International Journal of Advanced Manufacturing Technology. - 2009. - Vol. 42/7. - P. 813-821.

6. Tanovic Lj. Experimental Investigation of Microcutting Mechanisms in Marble Grinding / Lj.Tanovic, P.Bojanic, R.Puzovic // Journal of Manufacturing Science and Engineering. - 2009. - Vol. 131/6. - 064507.

7. Experimental Investigation of Microcutting Mechanisms in Oxide Ceramic CM332 / Lj.Tanovic, P.Bojanic, R.Puzovic, M.Milutinovic // Journal of Manufacturing Science and Engineering. - 2011. - Vol. 133/2. - 024501.

8. Experimental Investigation of Microcutting Mechanisms in Granite Grinding / G.Mladenovic, P.Bojanic, Lj.Tanovic, S.Klimenko // Journal of Manufacturing Science and Engineering. - Transactions ASME. - 2015. Vol. 137/3.

9. Stojadinovic S. Micro-Cutting Mechanisms in Silicon Nitride Ceramics Silinit R Grinding / S.Stojadinovic, L.Tanovic, S.Savicevic // Journal of The Chinese Society of Mechanical Engineers. - 2015. - Vol. 36/4. - P. 291-297.

10. Experimental Examination of the Impact of Tool Radius on Specific Energy in Microcutting of Granite / M.Pjevic, Lj.Tanovic, G.Mladenovic, B.Markovic // Journal of Manufacturing Science and Engineering. - Transactions ASME. - 2017. - Vol. 139/4

\section{References:}

1. Ehmann, K.F., Bourell, D., Culpepper, M.L. and other (2007), «Micromanufacturing: International Assessment of Research and Development», Springer.

2. Katz, Z. and Tibbles, C.J. (2005), «Analysis of Micro-scale EDM Process», The International Journal of Advanced Manufacturing Technology, Vol. 25, pp. 923-928,

3. [Online], available at: www.jpsalaser.com

4. Saotome, Y. and Okamoto, T. (2001) «An in-situ incremental microforming system for three-dimensional shell structures of foil materials», Journal of materials processing technology, Vol. 113, $636 \mathrm{p}$. 
5. Glavonjic, M., Milutinovic, D. and Zivanovic, S. (2009), «Functional simulator of 3-axis parallel kinematic milling machine», International Journal of Advanced Manufacturing Technology, Vol. 42/7, pp. 813-821.

6. Tanovic, Lj., Bojanic, P. and Puzovic, R. (2009), «Experimental Investigation of Microcutting Mechanisms in Marble Grinding», Journal of Manufacturing Science and Engineering, Vol. 131/6, 064507.

7. Tanovic, Lj., Bojanic, P., Puzovic, R. and Milutinovic, M. (2011), «Experimental Investigation of Microcutting Mechanisms in Oxide Ceramic CM332», Journal of Manufacturing Science and Engineering, Vol. 133/2, 024501.

8. Mladenovic, G., Bojanic, P., Tanovic, Lj. and Klimenko, S. (2015), «Experimental Investigation of Microcutting Mechanisms in Granite Grinding», Journal of Manufacturing Science and Engineering, Transactions ASME, Vol. 137/3.

9. Stojadinovic, S., Tanovic, L. and Savicevic, S. (2015), «Micro-Cutting Mechanisms in Silicon Nitride Ceramics Silinit R Grinding», Journal of The Chinese Society of Mechanical Engineers, Vol. 36/4, pp. 291-297.

10. Pjevic, M., Tanovic, Lj., Mladenovic, G. and Markovic B. (2017), «Experimental Examination of the Impact of Tool Radius on Specific Energy in Microcutting of Granite», Journal of Manufacturing Science and Engineering, Transactions ASME, Vol. 139/4.

Танович Любодраг - доктор технических наук, профессор, машиностроительный факультет Университета в Белграде, Сербия.

Научные интересы:

- производительные технологии;

- технологическое оборудование.

E-mail: 1tanovic@mas.bg.ac.rc. 